\title{
ON CREATING A "POWERFUL SCIENTIFIC AND TECHNOLOGICAL BASE" AND THE NECESSITY OF STRENGTHENING STATE SUPPORT OF SCIENTISTS AND INNOVATIVE BUSINESS IN RUSSIA ${ }^{1}$
}

\author{
Andrey V. Klypin \\ Russian Research Institute of Economics, Politics and Law in Science and Technology (RIEPL), \\ Moscow, Russian Federation
}

\begin{abstract}
The article is a research response to the task of developing the scientific and technological base set by the President of Russia in his message to the Federal Assembly in 2019. The scientific and technological base is revealed as a more comprehensive concept than a concept that includes only material and technical objects, in particular, it accommodates human resources engaged in research and development. The author reveals insufficiency of current measures of state support for researchers and developers, which boil down mainly to competitive financing of scientists and little-demanded tax breaks for innovative business. The paper proves several measures to strengthen the basic support of research personnel and technological business. There is a need not only to implement large scientific and technological infrastructure projects, but also increase the volume of budget (basic) support for researchers and developers through the growth of actual wages at the rate of the full working rate, provide preferential mortgage loans, expand tax incentives for innovative business, as well as develop a "qualified customer" model. The analysis is performed on the basis of studying Russian regulatory legal acts defining the state scientific and technical policy, articles of Russian scientists as well as materials of Russian and international statistical databases. The results of the study may be used by representatives of the executive authorities, as well as a wide range of specialists interested in the problems of science and technology policy in Russia.

Key words: scientific and technological base, scientific and technological projects, research and development infrastructure, budget financing, competitive financing, innovative business, tax breaks, qualified customer.

Citation. Klypin A.V. On Creating a "Powerful Scientific and Technological Base" and the Necessity of Strengthening State Support of Scientists and Innovative Business in Russia. Journal of Volgograd State University. Economics, 2019, vol. 21, no. 3, pp. 143-157. (in Russian). DOI: https://doi.org/10.15688/ek.jvolsu.2019.3.13
\end{abstract}

\section{О СОЗДАНИИ «МОЩНОЙ НАУЧНО-ТЕХНОЛОГИЧЕСКОЙ БАЗЫ» И НЕОБХОДИМОСТИ УСИЛЕНИЯ ГОСУДАРСТВЕННОЙ ПОДДЕРЖКИ УЧЕНЫХ И ИННОВАЦИОННОГО БИЗНЕСА В РОССИИ ${ }^{1}$}

\author{
Андрей Владимирович Клыпин \\ Российский научно-исследовательский институт экономики, политики и права \\ в научно-технической сфере (РИЭПП), г. Москва, Российская Федерация
}

Аннотация. Статья является исследовательским откликом на задачу по развитию научно-технологической базы, поставленную Президентом России в Послании Федеральному собранию в 2019 году. Научнотехнологическая база раскрывается в качестве более обширного понятия. Оно включает в себя не только материально-технические объекты - в него укладываются человеческие ресурсы, занятые исследованиями и разработками. Выявляется недостаточность текущих мер государственной поддержки исследователей и разработчиков, которые сводятся преимущественно к конкурсному финансированию ученых и маловостребованным налоговым льготам для инновационного бизнеса. Обосновывается необходимость не только реализации крупных научно-технологических инфраструктурных проектов, но и увеличения объемов бюджетной 
(базовой) поддержки исследователей и разработчиков через рост фактических заработных плат из расчета полной рабочей ставки, предоставление льготных ипотечных кредитов, расширение налоговых льгот для инновационного бизнеса, а также развитие модели «квалифицированного заказчика». Анализ проводился на основе изучения российских нормативных правовых актов, определяющих государственную научно-техническую политику, а также материалов российских и международных статистических баз данных. Результаты исследования применимы для представителей органов исполнительной власти, а также широкого круга специалистов, интересующихся проблемами научно-технологической политики в России.

Ключевые слова: научно-технологическая база, научно-технологические проекты, инфраструктура исследований и разработок, бюджетное финансирование, конкурсное финансирование, инновационный бизнес, налоговые льготы, квалифицированный заказчик.

Цитирование. Клыпин А. В. О создании «мощной научно-технологической базы» и необходимости усиления государственной поддержки ученых и инновационного бизнеса в России // Вестник Волгоградского государственного университета. Экономика. - 2019. - Т. 21, № 3. - C. 143-157. - DOI: https://doi.org/ 10.15688/ek.jvolsu.2019.3.13

\section{Введение}

В Послании Федеральному собранию в 2019 г. Президент России в качестве последнего из четырех приоритетов для решения системных проблем экономики отметил подготовку современных кадров и создание мощной научно-технологической базы [Послание ...]. Тезис прозвучал таким образом, что акцент в нем был сделан на кадровой составляющей, а слова о науке выступили своего рода добавочным звеном, однако то, что научно-технологическое развитие вошло в список приоритетных направлений государственной политики, нельзя не считать положительным аспектом. В то же время, исходя из характера поставленных задач, есть риск, что заявленные меры могут стать малодейственными инструментами по развитию сферы НИОКР и инноваций в России, поскольку упускаются из виду вопросы по усилению бюджетной (базовой) поддержки научно-исследовательского персонала, а основным механизмом финансовой поддержки ученых и разработчиков остается конкурсное финансирование. При этом стимулирование инновационной активности бизнеса с помощью имеющихся налоговых льгот является непопулярной мерой, что также выступает сдерживающим фактором.

На протяжении последних лет финансовая модель российского сектора исследований и разработок претерпевала существенные изменения. Это происходило в части привязки финансирования НИОКР к конечной результативности научно-исследовательских организаций [Денисов и др., 2016; Ильина,
2016], перехода от государственного сметного финансирования исследований и разработок к конкурсным механизмам (со стимулирующими выплатами) в рамках государственных заданий бюджетных учреждениям [Качак и др., 2012], роста федеральных расходов на государственные научные фонды [Ильина и др., 2017], концентрации основных объемов расходов на науку в ограниченном числе отраслевых государственных программ [Клыпин, 2016].

Нефтяной кризис 2014 г. с последующей девальвацией рубля, а также западные санкции существенно сжали возможности федерального бюджета, что (в отсутствие рассмотрения гражданской науки в качестве одного из ключевых приоритетов национальной политики) негативно отразилось на финансовой поддержке исследований и разработок со стороны государства. Непоследовательность мер по финансовому обеспечению науки со стороны государства проявилась в сокращении в определенные периоды темпов роста финансирования фундаментальных исследований при росте расходов на прикладную науку (2011-2012 г.) и наоборот (2016-2017 гг.) (см. рисунок).

Наряду с этим при падении общих объемов расходов федерального бюджета на гражданскую науку в 2015-2016 гг. произошло существенное увеличение финансирования прикладных исследований в области национальной обороны, что свидетельствует о приоритизации науки оборонного характера со стороны государства в этот период. В 2017 г., согласно данным федерального закона «Об ис- 
A.B. Клыпин. О создании «мощной научно-технологической базы»
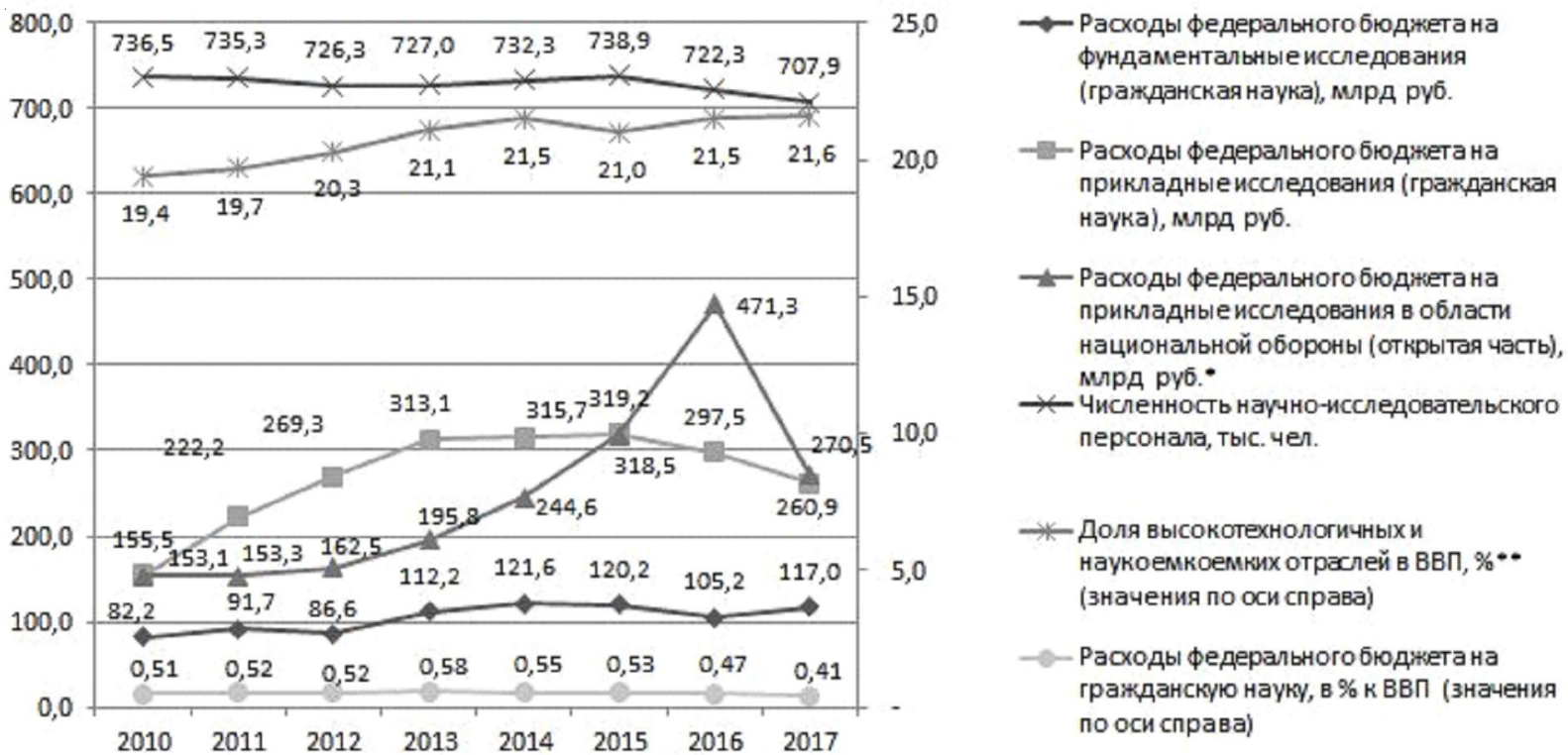

Рисунок. Динамика некоторых показателей научно-технологического комплекса России в 2010-2017 гг.

Примечание. Составлено автором по: [Федеральные законы ...; Численность персонала ...; Доля ...; Финансирование ...]. В части расходов на прикладные научные исследования в области национальной обороны учитываются расходы по разделу/подразделу 0208 кодов бюджетной классификации «Прикладные научные исследования в области национальной обороны». Данные по доле высокотехнологичных и наукоемких производств за 2010-2013 гг. приведены в соответствии с Общероссийским классификатором видов экономической деятельности ОКВЭД 2007, данные за 2014-2017 гг. приведены в соответствии с классификатором ОКВЭД2.

полнении федерального бюджета за 2017 год», произошло существенное снижение объемов расходов на прикладные научные исследования в области национальной обороны, однако их объем по-прежнему превышает расходы на прикладные научные исследования гражданского назначения.

В конце 2018 г., перед Посланием Президента Федеральному собранию, на государственном уровне был принят важный документ, определяющий во многом содержание дальнейшей государственной научно-технической политики в стране, - национальный проект «Наука» (далее - НП «Наука»). НП «Наука» явился следствием задач, поставленных Президентом России в «майском указе» 2018 г. [О национальных ...] и озвученных главой государства на заседании Совета при Президенте по науке и образованию в ноябре 2018 г. [Стенограмма ...], в частности о необходимости получения прорывных открытий и разработок, которые позволят создавать отечественную продукцию мирового уровня.

Согласно НП «Наука» [Паспорт ...] работа по развитию сектора исследований и раз- работок в России должна строиться по 3 основным направлениям (в рамках федеральных проектов) и включать развитие: 1) научной и научно-производственной кооперации; 2) передовой инфраструктуры для проведения исследований и разработок; 3 ) кадрового потенциала в сфере исследований и разработок (см. таблицу).

Анализ положений федеральных проектов НП «Наука» показал, что первые два из них имеют явную нацеленность на развитие (строительство) крупных научных и научнопроизводственных комплексов и обеспечение исследователей научным оборудованием (научно-образовательные центры, научные центры мирового уровня, центры коллективного пользования и уникальные научные установки, установки класса «мегасайенс»). В основу третьего федерального проекта, вместе с поддержкой аспирантуры, а также лабораторий и проектов под руководством молодых исследователей, заложено создание центров развития компетенций руководителей научных, научно-технических проектов и лабораторий. Однако в качестве единственного механизма 
Федеральные проекты в структуре национального проекта «Наука»

\begin{tabular}{|l|l|}
\hline \multicolumn{1}{|c|}{ Наименование федеральных проектов } & \multicolumn{1}{|c|}{ Задачи федеральных проектов } \\
\hline Развитие научной и научно-произ- & $\begin{array}{l}\text { 1. Создание не менее 15 научно-образовательных центров мирово- } \\
\text { го уровня на основе интеграции университетов и научных органи- } \\
\text { заций и их кооперации с организациями, действующими в реаль- } \\
\text { ном секторе экономики. } \\
\text { 2. Создание научных центров мирового уровня, включая сеть меж- } \\
\text { дународных математических центров и центров геномных иссле- } \\
\text { дований }\end{array}$ \\
\hline $\begin{array}{l}\text { Развитие передовой инфраструктуры } \\
\text { для проведения исследований и разра- } \\
\text { боток в Российской Федерации }\end{array}$ & $\begin{array}{l}\text { организаций, выполняющих научные исследования и разработки. } \\
\text { 2. Развитие передовой инфраструктуры научных исследований и } \\
\text { разработок, инновационной деятельности, включая создание и раз- } \\
\text { витие сети уникальных установок класса «мегасайенс» }\end{array}$ \\
\hline $\begin{array}{l}\text { Развитие кадрового потенциала в сфе- } \\
\text { ре исследований и разработок }\end{array}$ & $\begin{array}{l}\text { Формирование целостной системы подготовки и профессиональ- } \\
\text { ного роста научных и научно-педагогических кадров, обеспечи- } \\
\text { вающей условия для осуществления молодыми учеными научных } \\
\text { исследований и разработок, создания научных лабораторий и кон- } \\
\text { курентоспособных коллективов }\end{array}$ \\
\hline
\end{tabular}

Примечание. Составлено автором по: [Паспорт ...].

финансирования развития кадрового потенциала в науке в нем указан только механизм «грантовой» поддержки научно-исследовательского персонала (или иначе - механизм конкурсного финансирования). Таким образом, в направленности инструментов поддержки сектора исследований и разработок НП «Наука» явно виден акцент на развитие преимущественно научно-технологической инфраструктуры и приборной базы. При этом касательно основных принципов государственного финансирования сектора исследований и разработок выдерживается ранее намеченный Правительством России тренд усиления конкурсных процедур финансирования посредством грантов.

Однако динамика развития российской сферы НИОКР в настоящий момент свидетельствует о том, что та финансовая поддержка ученых, которая имеется, недостаточна для решения задачи научно-технологического прорыва. Бизнесу, от которого государство ждет инвестиций в науку, также нужны новые материальные стимулы. Статистика показывает уменьшение численности научно-исследовательского персонала в России в 20152017 гг. (см. рисунок), при этом с 2000 г. данный показатель снизился на $20 \%$ и расчеты некоторых авторов обосновывают перспективу его дальнейшего снижения [Михалева, 2015]. Кроме того, сегмент высоких техноло- гий растет весьма слабо ${ }^{2}$, что не соответствует ранее поставленной Президентом России задаче по увеличению доли продукции высокотехнологичных и наукоемких отраслей в экономике на $30 \%$ относительно уровня 2011 г. [О долгосрочной ...]

\section{О сущности понятия} научно-технологической базы и реализуемых в настоящее время в России мерах по поддержке ученых и инновационного бизнеса

Анализируя положения Послания Президента Федеральному собранию 2019 г. в части, касающейся научно-технологического развития, следует отметить, что, исходя из опыта развитых стран, технологический прорыв в экономике, как правило, всегда связан с развитием высококлассной научно-технологической базы, что обеспечивается существенными финансовыми вложениями в создание и поддержку современных научных объектов и оборудования. Однако следует уточнить, что передовая научная инфраструктура и научные кадры - сущности единого целого. Доказательным аргументом в пользу данного положения является определение разницы между понятиями «материально-техническая база» науки и «научно-технологический потенциал». Так, руководствуясь ресурсным 
подходом, под научно-технологическим потенциалом следует понимать набор человеческих, материально-технических, а также информационных ресурсов [Семенов, 2013], а материально-техническая база в рамках организационного подхода предстает только одним из элементов научно-технологического потенциала (относительно статичным) [Парфенова и др., 2016]. Таким образом, при использовании любого из названных подходов «научно-технологический потенциал» является понятием более обширным, чем «материальнотехническая база». Возникает вопрос: возможно ли отождествлять понятия «научно-технологическая база» и «научно-технологический потенциал»? При этом целесообразно учесть, что «применительно к экономической деятельности термин “потенциал” практически всегда семантически связан со способностью и возможностью какого-либо общественного актора выполнить поставленные при определенных условиях им самим или извне задачи» [Фролов и др., 2014]. Ответ на этот вопрос зависит от того, насколько высока значимость проблематики, на решение которой направлено использование данных понятий. И следует допустить, что, когда речь идет о решении задач государственного масштаба, связанных с развитием науки и технологий в стране в целом, целесообразным является более широкое представление исследуемого объекта.

В этой связи современная научно-технологическая база - это широкое понятие, включающее в себя не только передовые научные объекты, здания и сооружения, приборы и оборудование, но также и научно-исследовательский персонал, реализуюший свою деятельность с их использованием. Причем, принимая в расчет численность такого персонала, следует иметь в виду не только научно-исследовательские кадры, вовлеченные в создание новейших военных разработок для защиты от внешних угроз, но и кадры, которые решают фундаментальные и прикладные научные задачи в гражданских отраслях, в том числе в целях создания конкурентной продукции для внутреннего потребления и экспорта. Критически важно, чтобы в состав такой продукции входили современные товары повседневного спроса: экологичные продукты питания, высокотехнологичная одежда и обувь, инновационные лекарственные препараты, машины и оборудование, строительные технологии. Обоснованием тому являются результаты анализа, показывающие, насколько высока в настоящее время зависимость страны от зарубежных поставок по этим направлениям [Бадирова и др., 2017; Кругляк и др., 2018; Миронова, 2018].

Отсюда следует предположить, что развитие научно-технологической базы не должно сводиться к реализации преимущественно инфраструктурных проектов и развитию в основном конкурсного финансирования научных исследований и разработок, а должно включать в себя совершенствование и расширение других мер финансовой поддержки ученых и разработчиков, а также инновационного бизнеса, под которым следует понимать совокупность компаний, активно использующих результаты интеллектуальной деятельности и выпускающих продукцчию (товары или услуги), существенно превосходящую по некоторым свойствам предшествующие аналоги, или продукциюю, совершенно новую для рынка.

Для того чтобы доказать необходимость дополнительных мер поддержки научно-исследовательского персонала, а также инновационного бизнеса в России, далее проведем обзор задач научно-технической политики, поставленных на государственном уровне, в ретроспективе. Для этого обратимся к «майским указам» Президента России, подписанным в 2012 г., в которых содержалось более 200 поручений, направленных на улучшение жизни населения России.

«Майские указы» 2012 г. закрепляли множество задач по развитию науки и технологий с числовыми параметрами: рост высокотехнологичного сектора и расходов на НИОКР, включая финансирование научных фондов, повышение позиций российских университетов в мировых рейтингах, увеличение числа публикаций исследователей в журналах мирового уровня, рост зарплат научных работников.

Оставив за рамками данной статьи исследование причин неисполнения указов Президента касательно роста общего объема расходов на НИОКР и доли высокотехнологичных производств, следует отметить, что за- 
дачи по повышению средней заработной платы научно-педагогических кадров и обеспечению их комфортным жильем остались также нерешенными. Причем вызывает серьезные опасения формальность в достижении показателя, связанного с ростом заработной платы преподавателей вузов и научных сотрудников. Известно, что зарплаты ученых формально выросли и доведены до уровня $200 \%$ от средней по региону. Однако во многих случаях произошло это путем дробления ставок [Ушаков, 2018]. То есть по факту в научных и образовательных организациях научно-исследовательский персонал, оформленный на 0,25-0,5 ставки, продолжил осуществлять свою деятельность в течение полного рабочего дня, получая при этом прежнюю заработную плату. Однако при пересчете полученного дохода в пропорциях полной ставки заработная плата персонала (данные по которой формируют статистические службы) становится соизмеримой с 2-кратной по региону, что, безусловно, недопустимо.

Также на текущий момент остается нереализованным развитие особых условий выдачи банковских займов для научно-исследовательского персонала с целью покупки жилья. На фоне экономической нестабильности и девальвации рубля в конце 2014 г. программа льготного ипотечного кредитования молодых ученых через АИЖК была упразднена в короткие сроки. Следует обратить внимание на тот факт, что в федеральном бюджете на 2019 и 2020-2021 гг. на мероприятия по обеспечению жильем молодых ученых и строительство общежитий заложено всего около 289,8 млн руб., в то время как объем субсидий российским кредитным организациям и акционерному обществу «ДОМ.РФ» (ранее АИЖК) на возмещение недополученных доходов по выданным жилищным кредитам в 2019 г. должен составить 9,2 млрд руб., в 2020 г. - 11,5 млрд руб., в 2021 г. - 11,1 млрд рублей [О федеральном ...]. На настоящий момент к действующим ипотечным программам «ДОМ.РФ» относятся программы покупки новостроек, приобретения готового жилья, перекредитования и рефинансирования, покупки квартир под залог, семейная ипотека (для семей с 2 детьми и более), а также военная ипотека для участников накопительно-ипотеч- ной системы жилищного обеспечения военнослужащих. Льготная ипотечная программа для ученых, реализуемая на общегосударственном уровне через АО «ДОМ.РФ», отсутствует. Льготная ипотека для ученых действует только в Московской области [Программа ...], однако претендовать на нее могут исключительно исследователи, участвующие в разработке технологий, соответствующих перечню критических технологий Российской Федерации (Указ Президента России от 07.07.2011 № 899), или те, кто участвует в ОКТР с практическим применением, включая оборонный заказ.

Данным проблемам нужна основательная проработка. Вопрос реального повышения заработной платы научно-исследовательского персонала и преподавателей должен находиться на повестке профильных органов исполнительной власти и предполагать разработку комплекса мер и последовательных корректирующих мероприятий. Что касается возобновления программ льготной ипотеки для ученых на общегосударственном уровне, это требует в первую очередь инициативных и согласительных действий со стороны не только органов исполнительной власти, но и Правительства России. Логика в решении данных вопросов предлагается следующая. Если в стране стоит задача добиться успехов в научно-технологическом развитии в гражданском секторе, причем сопоставимых с развитием технологий для ОПК, то материальное обеспечение и льготы по жилью для ученых должны быть соизмеримы с льготами и денежным содержанием для военных.

В последние годы проблемам государственной финансовой политики в части поддержки российских исследователей посвящались работы, в которых критично оценивались шансы практической пользы от увеличения доли конкурсного финансирования в общем объеме государственных средств, направляемых на науку. В.Л. Тамбовцевым, в частности, приводились доказательства отсутствия научной обоснованности такой политики с указанием, среди прочего, на то, что в России она усиливает неопределенность жизненных перспектив для исследователей в силу низкой емкости рынка профессионального труда и небольшого числа фондов, финансирующих исследования [Тамбовцев, 2018]. Н.Г. Кура- 
кова при этом обращала внимание на сложность в проведении экспертизы конкурсных заявок и риски формализации высоких результатов научной деятельности в качестве одних наукометрических показателей [Куракова, 2015], по которым оцениваются финансируемые из бюджетных средств научно-исследовательские проекты в России.

Что касается государственного финансирования инновационного бизнеса, то есть инновационных предприятий и организаций, активно ведущих работу в сфере НИОКР, анализ показывает, что, несмотря на использование в России многих инструментов поддержки инноваторов, в этой области по-прежнему присутствует ряд серьезных проблем и недостатков. Их решению, согласно ряду исследований [Ильина и др., 2016], должно способствовать развитие механизмов налогового стимулирования бизнеса к вложениям в НИОКР. При этом, как отмечают другие авторы [Черных и др., 2018], льготы не должны быть направлены на поддержку только лишь проектов, соответствующих текущим научно-технологическим приоритетам в стране (они ведь могут меняться. $A . K$.), что подчеркивает необходимость проведения гибкой политики в ходе государственной поддержки инновационного бизнеса. Исследователи также обращают внимание на целесообразность освобождения инновационных компаний, использующих в своем производстве результаты интеллектуальной деятельности, от уплаты НДС (на срок до 5 лет) и изменения принципов учета произведенных расходов на исследования и разработки. В частности, в случае использования инвестиционного налогового кредита предлагается переход в сторону фактического снижения суммы исчисляемого налога на прибыль взамен отсрочки по его уплате [Черных и др., 2018]. Кроме того, подчеркивается необходимость введения ускоренных норм амортизации оборудования и зданий, используемых для их осуществления, и возможности стопроцентного списания расходов на приобретение активов, применяемых в инновационной деятельности в первый год реализации такой деятельности [Седаш и др., 2018]. Следует отметить, что данные меры в различных зарубежных странах вариативны [Ермакова и др., 2015] и практикуются уже многие годы, доказав свою эффективность.

\section{Текущие задачи по развитию научно-технологической базы, проблемы их реализации и предложения по усилению бюджетной (базовой) поддержки исследователей и разработчиков, а также инновационного бизнеса}

В соответствии с Посланием Президента Федеральному собранию, «майским указом» Президента России 2018 г. и НП «Наука» в России планируется создание 15 научно-образовательных центров мирового уровня, реализация крупных проектов по развитию инфраструктуры для исследований и разработок и приборной базы. Данные меры представляются обширными, однако возникает вопрос: достаточно ли этого, чтобы изменить негативный тренд снижения численности научного персонала и низкие темпы роста высокотехнологичных производств? Проблема в том, что в стране ранее уже выдвигались и реализовались в той или иной степени инициативы по развитию масштабных научно-технологических проектов и стимулированию инноваций в отдельных регионах. Существенные объемы государственных средств направлены на создание инновационного центра «Сколково», технопарков в сфере высоких технологий, особых экономических зон технико-внедренческого типа, инновационных территориальных кластеров, национальных исследовательских и федеральных университетов, других научно-технологических и инновационных государственных проектов. Однако на основе данных Росстата можно сделать вывод о том, что в настоящее время обрабатывающие производства в стране - в числе секторов экономики едва ли ни с наименьшими темпами роста (2018 г. - 1,5 \%) [Клыпин].

В своем Послании Федеральному собранию Президент обратил внимание на потребность в экономике, растущей темпами выше среднемировых, а также озвучил широкий набор новых мер социальной поддержки граждан, среди которых субсидии врачам и учителям для переезда в сельскую местность («Земский доктор», «Земский учитель»), развитие предпринимательских инициатив, поддержка рабочих специальностей, а также трудоустройство безработных через механизм 
социального контракта. При этом, как было отмечено выше, основные меры и задачи в части поддержки специалистов в сфере науки и технологий можно свести, по сути, к поддержке инфраструктурных научно-технологических проектов и развитию конкурсного финансирования кадров, что в силу приведенных в этой статье обоснований обусловливает необходимость реализации альтернативных мер государственной научно-технической политики.

Не требует опровержения целесообразность задачи развития кадрового потенциала, прозвучавшей в Послании Президента Федеральному собранию 2019 г., в частности «о необходимости поддержки специалистов, способных работать на передовых производствах, создавать и использовать прорывные технические решения» [Послание ...]. Однако такого рода специалисты в значительной части и представляют тот научно-исследовательский персонал, численность которого в последнее время в стране снижается и который критически необходим для технологического прорыва экономике. Также существенным является формирование выгодных условий для представителей инновационного бизнеса, которые становятся завершающим звеном в цепочке создания прорывных исследований и технологий, их трансфера и воплощения в новой продукции. В современном мире потребность в создании благоприятных условий для материального стимулирования врачей и учителей, военнослужащих, а также представителей рабочих профессий остается крайне важной для любого государства, и Россия не исключение. Однако анализ показывает, что без роста внимания к деятельности исследователей и разработчиков, отнесения их работы в ранг по-настоящему престижной и уважаемой (что может на практике быть реализовано в первую очередь через увеличение объемов их базового денежного содержания) невозможно добиться прорыва в гражданских отраслях экономики.

Для России с 19-миллионным населением с денежными доходами ниже величины прожиточного минимума [Численность населения ...] комплексная долгосрочная социальная поддержка граждан, отвечающая их потребностям, возможна не столько при ускоренном экономическом росте тем- пами выше среднемировых, сколько при поступательном экономическом развитии интенсивного типа с ярко выраженной научно-технологической составляющей. Представляется, что, формируя такую экономику, требуется направлять существенную часть финансовых средств в науку, знания, технологии, компетенции, причем на системной основе и в значительных объемах, реализуя усиленные меры по поддержке ученых и разработчиков. Однако сведение такой поддержки только к конкурсному финансированию и развитию инфраструктуры в отсутствие благоприятных условий денежного содержания научно-исследовательского персонала и льготного налогообложения для инновационного бизнеса, по всей вероятности, является весьма узконаправленной государственной политикой. Тогда какая государственная научно-техническая политика является комплексной и в чем заключаются альтернативные меры бюджетной (базовой) поддержки ученых и инновационного бизнеса?

Комплексная государственная научно-техническая политика - это полити$\kappa a$, которая формирует одновременно и благоприятные материальные условия (денежное содержание), и необходимые технические условия (здания и сооружения, приборы и оборудование) для сектора исследований и разработок и включает в себя не только конкурсную поддержку получателей государственных средств, но и достойное бюджетное (базовое) обеспечение персонала, занятого в сфере НИОКР, а также благоприятные условия для функционирования и развития инновационного бизнеса. В контексте реализации новых мер государственной научно-технической политики это подразумевает необходимость не только развития масштабных инфраструктурных проектов и поддержки конкурсного финансирования, которые также важны, но и осуществление стабильных инвестиций в фундаментальную науку, а также стимулирование бизнеса к прикладным научным исследованиям. Средствами для достижения такой цели являются, в том числе, бюджетное обеспечение научно-исследовательского персонала и научных организаций, предоставление действенных налоговых льгот инновационному 
бизнесу вместе с развитием модели «квалифицированного заказчика», в которой государственные, научные организации и бизнес разделят ответственность по финансированию и коммерциализации результатов интеллектуальной деятельности, а предприятия реального сектора экономики обеспечат заказ, оценку и приемку результатов НИОКР [Клыпин и др., 2019]. В модели «квалифицированного заказчика инновационный бизнес выступает основным заказчиком научно-исследовательских работ, их инвестором (соинвестором), а также гарантом коммерциализации полученных в ходе их проведения РИД. Государственные организации при этом не только осуществляют кураторскую (координационную) функцию в управлении процессом исследований и разработок с использованием государственных средств, финансируя или софинансируя такие проекты в разных объемах в зависимости от их жизненного цикла, но и выступают гарантом предоставления льгот и преференций для инновационно активных компаний в случае их участия в модели «квалифицированного заказчика».

Таким образом, с учетом проведенного исследования обусловливается необходимость реализации следующих первоочередных мер государственной научно-технической политики, способствующих созданию благоприятных условий деятельности для ученых и развития инновационного бизнеса:

1) увеличение заработной платы научноисследовательского персонала, включая аспирантов и докторантов, из расчета полной рабочей ставки;

2) принятие на федеральном и региональных уровнях программы льготной ипотеки для молодых ученых через АИЖК (АО «ДОМ.РФ»);

3) внедрение действенных налоговых льгот для инновационного бизнеса в проектах широкого профиля;

4) развитие модели «квалифицированного заказчика» с предоставлением от государства льгот и преференций для принимающих в ней участие инновационных компаний.

В качестве вспомогательной меры можно выделить принятие дополнительных льгот для успешных в науке учащихся средних и высших учебных заведений, включая учебные практики и стажировки в зарубежных научнообразовательных учреждениях и на коммер- ческих предприятиях, а также создание максимально благоприятных условий для них в дальнейшем в России (в данном случае применим механизм конкурсного финансирования). Опыт Китая показывает высокую степень отдачи от подобных мер.

При этом главным является необходимость пересмотра политики государственного финансирования исследований и разработок в сторону не только развития механизмов конкурсов, но и изыскания возможностей для увеличения базового финансового обеспечения сферы науки и технологий (бюджетное финансирование), которое должно осуществляться на существенном уровне в независимости от текущей успешности исследователей и разработчиков в процедурах конкурсного распределения государственных средств, а также создание максимально благоприятных условий для ведения в стране инновационного бизнеса.

\section{Заключение}

В настоящее время российская экономика переходит в новую фазу развития с задачей технологического прорыва в гражданских отраслях, имея при этом неблагоприятный внешний фон, выраженный в давлении санкциями и военно-политических конфликтах, что сохраняет тренд существенных государственных затрат на военную науку и разработки. Безусловно, для любого государства важными являются защита границ и противостояние внешним угрозам при наличии работоспособного ОПК с новейшими технологиями, и не следует отрицать достигнутые успехи России в данной области. Однако проблема заключается в том, что в настоящее время сильная армия является основной составляющей мощи Российского государства и ее суверенитета. Вместе с тем в современном мире, и ущерб, полученный от санкций [Глазьев и др., 2018; Гринберг, 2016], это показал, не менее важно иметь мощную экономику, основанную на знаниях, научных достижениях и технологиях. Однако добиться этого невозможно без существенных бюджетных затрат на исследования и разработки в гражданских секторах. Стоит при этом напомнить, что в процентах от ВВП общие затраты на науку в России су- 
щественно уступают странам - лидерам в сфере высоких технологий. В Южной Корее на НИОКР тратят около 4,6 \% от стоимости всей произведенной за год в стране продукции, в Израиле $-4,5 \%$, в Японии - 3,2 \%, в США - 2,8 \%, в Китае - 2,1\%. В России показатель равен всего 1,1 \% [OECD Data]. Объем федеральных затрат на гражданскую науку также в процентах от ВВП в России имеет нисходящую динамику: 0,58 \% в 2013 г. и $0,41 \%$ в 2017 г. [Финансирование ...] (см. рисунок). Также имеются существенные проблемы в научно-образовательном секторе, в котором наблюдается не только «утечка умов» (переезд ученых и выпускников вузов в другие страны), но и «утечка идей» (реализация научных исследований российскими авторами по заказу иностранных работодателей) [Карнаух, 2019]. Данные обстоятельства требуют пересмотра принципов и акцентов в государственной финансовой политике в секторе исследований и разработок, развития ее в сторону комплексности, многомерности, а также системности и последовательности.

Новая волна мер социальной поддержки граждан, озвученных в Послании Президента России в 2019 г., включая поддержку врачей, учителей и другие меры, могут купировать отдельные «симптомы болезни» действующей российской социально-экономической системы, но способны ли они «излечить» эту болезнь целиком? Анализ показывает, что существуют вполне обоснованные риски, что реализация мер по развитию преимущественно передовой инфраструктуры для проведения исследований и разработок и дальнейшему развитию механизмов конкурсного финансирования может не привести к требуемому результату технологического прорыва России.

Принимая за основу проблему экономического выбора, возникает вопрос: что лучше? Вложить сегодня многомиллиардные объемы государственных средств в создание и развитие крупных инфраструктурных проектов и финансовую поддержку ограниченного числа «избранных» ученых через конкурсы, приняв на себя риски отсутствия в долгосрочной перспективе необходимой критической массы научно-исследовательского персонала, работающего на вновь созданных научно-технологических объектах? Или направить часть имеющихся средств на улучшение базовых материальных условий ученых и действенные налоговые льготы и преференции для инновационных компаний, которые, получив гарантии финансирования своего труда и реальной поддержки со стороны государства, смогут закрепиться в науке и бизнесе и реализовать имеющийся потенциал в научных открытиях, разработках и новой для рынка высокотехнологичной продукции?

С учетом проведенного анализа необходимость выбора усиления бюджетной (базовой) поддержки ученых и разработчиков и развития механизма налоговых льгот и преференций для инновационного бизнеса можно считать доказанной.

\section{ПРИМЕЧАНИЯ}

${ }^{1}$ Исследование выполнено в рамках государственного задания «Анализ востребованности научных (научно-технических) результатов» (проект № 28.13353.2019 / 13.1; государственное задание № 075-00937-19-01).

The reported study was carried out in the framework of the state task "Analysis of the Demand for Scientific (Scientific and Technical) Results" (project number 28.13353.2019/13.1; state task number 075-00937-19-01).

2 Согласно Указу Президента Российской Федерации от 7 мая 2012 г. № 596 «О долгосрочной государственной экономической политике» к 2018 г. необходимо было увеличить долю продукции высокотехнологичных и наукоемких отраслей экономики в валовом внутреннем продукте в 1,3 раза относительно уровня 2011 года. То есть необходимо было довести ее до 25,6 \%. По факту этот показатель оказался равным 21,6 \% в 2017 г. и 21,1 \% в 2018 году.

\section{СПИСОК ЛИТЕРАТУРЫ}

Бадирова, К. И. Импортозависимость производства фармацевтических субстанций как проблема лекарственной безопасности Российской Федерации / К. И. Бадирова, Д. М. Слепнев // Инновации в здоровье нации : сб. материалов V Всерос. науч.-практ. конф. с междунар. участием, г. Санкт-Петербург, 8-9 нояб. 2017 г. СПб., 2017.-С. 99-103.

Глазьев, С. Ю. Оценка влияния санкций и других кризисных факторов на состояние российской экономики / С. Ю. Глазьев, В. В. Архипо- 
ва // Российский экономический журнал. 2018. - № 1. - C. 3-29.

Гринберг, Р. С. Любовь к санкциям как экономический мазохизм / Р. С. Гринберг // Мир перемен. Международный научно-общественный журнал. - 2016. - № 3. - С. 5-7.

Денисов, О. И. Методические проблемы и подходы к оценке результативности и эффективности НИОКР и инноваций / О. И. Денисов, С. Г. Фалько, В. П. Бойко // Инновации в менеджменте. - 2016. - № 2 (8). - С. 36-45.

Доля высокотехнологичных и наукоемких отраслей экономики в ВВП // Федеральная служба государственной статистики. - Электрон. текстовые дан. - Режим доступа: http://www. gks.ru/wps/wcm/connect/rosstat_main/rosstat/ ru/statistics/efficiency/\# (дата обращения: 02.05.2019). - Загл. с экрана.

Ермакова, Е. А. Налоговые кредиты в системе стимулирования инновационной активности / Е. А. Ермакова, Н. А. Ларионов // Управленец. - 2015. - № 2 (54). - С. 4-10.

Ильина, И. Е. Инструменты государственных инвестиций в сектор исследований и разработок и инновационную деятельность: зарубежный опыт / И. Е. Ильина, Е. А. Салицкая, О. Л. Сергеева // Формирование новой экономики и кластерные инициативы: теория и практика. СПб., 2016. - С. 459-485.

Ильина, И. Е. Инструменты поддержки исследований и разработок ведущих отечественных и зарубежных научных фондов / И. Е. Ильина, Е. Н. Жарова // Интеграция образования. 2017. - Т. 21, № 2 (87). - С. 164-183.

Ильина, И. Е. Результативность организаций, осуществляющих научную деятельность, как индикатор эффективности государственных расходов на НИОКР/ И. Е. Ильина // Новая экономическая реальность, кластерные инициативы и развитие промышленности (ИНПРОМ2016) : труды Междунар. науч.-практ. конф., 19-26 мая 2016 г. - СПб., 2016. - С. 178-182.

Карнаух И. В. Становление экономики знаний в России: проблемы и пути их решения // Вестник Волгоградского государственного университета. Серия 3, Экономика. Экология. - 2019. T. 21, № 1. - C. 66-74. - DOI: https://doi.org/ 10.15688/jvolsu3.2019.1.6.

Качак, В. В. Адаптивный подход к формированию объема финансирования государственного задания государственным учреждениям в части выполнения научных исследований / В. В. Качак, А. В. Журихин, А. М. Масленников // Инновации. - 2012. - № 7 (165). - С. 41-46.

Клыпин, А. В России вырос ВВП, а не экономика, и это не рекорд / А. В. Клыпин. - Электрон. тек- стовые дан. - Режим доступа: https://echo.msk. ru/blog/aklypin/2367625-echo/ (дата обращения: 02.05.2019). - Загл. с экрана.

Клыпин, А. В. Государственное финансирование прикладной науки в России / А. В. Клыпин // Наука. Инновации. Образование. - 2016. № 1 (19). - С. 34-54.

Клыпин, А. В. Модель «квалифицированного заказчика» в сфере НИОКР в России: определение основных свойств и характеристик / А. В. Клыпин, Е. В. Агамирова, Е. Н. Жарова // Управление наукой и наукометрия. - 2019. - № 2 (14). C. 224-247.

Кругляк, Л. И. Экономика импортозамещения: реалии и перспективы / Л. И. Кругляк, Т. Г. Баранчук // Материалы Всерос. науч.-практ. конф. «Национальная безопасность России: актуальные аспекты». - СПб. : ГНИИ «Нацразвитие», 2018.-С. 46-52.

Куракова, Н. Г. Об оптимизации системы формирования государственного задания на выполнение работ в сфере науки / Н. Г. Куракова // Экономика науки. - 2015. - Т. 1, № 3. - С. 221-235.

Миронова, О. А. Проблемы обеспечения продовольственной безопасности России на макро- и мезоуровне в условиях внешнеторговых санкций / О. А. Миронова // Economics. Law. State. - 2018. - № 1 (1). - C. 22-30.

Михалева, М. Н. Моделирование изменения численности российских исследователей и преподавателей высшей школы / М. Н. Михалева // Россия реформирующаяся. - 2015. - № 13. С. 347-359.

О долгосрочной государственной экономической политике. - Доступ из справ.-правовой системы «КонсультантПлюс». - Электрон. текстовые дан. - Режим доступа: http://www. consultant.ru/ document/cons_doc_LAW_129343/(дата обращения: 02.05.2019). - Загл. с экрана.

О национальных целях и стратегических задачах развития Российской Федерации на период до 2024 года. - Электрон. текстовые дан. - Режим доступа: http://kremlin.ru/acts/bank/43027 (дата обращения: 02.05.2019). - Загл. с экрана.

О производстве и использовании валового внутреннего продукта (ВВП) за 2018 год // Федеральная служба государственной статистики. Электрон. текстовые дан. - Режим доступа: http://www.gks.ru/bgd/free/b04_03/Isswww. exe/ Stg/d04/21.htm (дата обращения: 02.05.2019). Загл. с экрана.

О федеральном бюджете на 2019 год и на плановый период 2020 и 2021 годов. - Доступ из справ.правовой ситемы «КонсультантПлюс». Электрон. текстовые дан. - Режим доступа: http://www.consultant.ru/document/cons_doc_ 
LAW_312362/ (дата обращения: 02.05.2019). Загл. с экрана.

Парфенова, С. Л. Качественные изменения научно-технологического потенциала России / С. Л. Парфенова, Д. В. Золотарев, Е. Г. Гришакина // Наука. Инновации. Образование. 2016. - № 1 (19). - С. 9-33.

Паспорт национального проекта «Наука». - Электрон. текстовые дан. - Режим доступа: http:// static.government.ru/media/files/vCAoi8zEXRV Suy2Yk7D8hvQbpbUSwO8y.pdf(дата обращения: 02.05.2019). - Загл. с экрана.

Послание Президента Федеральному Собранию в 2019 г. - Электрон. текстовые дан. - Режим доступа: http://www.kremlin.ru/events/president/ news/59863 (дата обращения: 02.05.2019). - Загл. с экрана.

Программа «Социальная ипотека» в Московской области. - Электрон. текстовые дан. - Режим доступа: https://mosreg.ru/sobytiya/infografika/ programma-socialnaya-ipoteka-v-moskovskoyoblasti (дата обращения: 02.05.2019). - Загл. с экрана.

Седаш, Т. Н. Использование зарубежного опыта налогового стимулирования инноваций в России / Т. Н. Седаш, Е. Б. Тютюкина // Финансы и кредит. - 2018. - Т. 24. - Вып. 12. (780). - С. 2863 2875. -DOI: https://doi.org/10.24891/fc.24.12.2863.

Стенограмма заседания Совета по науке и образованию в 2018 г. - Электрон. текстовые дан. Режим доступа: http://www.kremlin.ru/events/ president/news/59203 (дата обращения: 02.05.2019). - Загл. с экрана.

Тамбовцев, В. Л. О научной обоснованности научной политики в РФ/ В. Л. Тамбовцев // Вопросы экономики. -2018 . - № 2. - С. 5-32.

Ушаков, Д. В. Социально-политические и экономические основания деформации социогуманитарной академической науки / Д. В. Ушаков // Вестник Хакасского государственного университета им. Н. Ф. Катанова. - 2018. - № 25. C. $124-128$.

Федеральные законы об исполнении федерального бюджета (2013 - 2017 гг.). - Доступ из справ.правовой системы «КонсультантПлюс». Электрон. текстовые дан. - Режим доступа: http://www.consultant.ru/document/cons_doc LAW_169502/ (дата обращения: 02.05.2019). Загл. с экрана.

Финансирование науки из средств федерального бюджета // Федеральная служба государственной статистики. - Электрон. текстовые дан. Режим доступа:http://www.gks.ru/wps/wcm/ connect/rosstat_main/rosstat/ru/statistics/ science_and_innovations/science/\# (дата обращения: 02.05.2019). - Загл. с экрана.
Фролов, И. Э. Научно-технологический потенциал России на современном этапе: проблемы реализации и перспективы развития / И. Э. Фролов, Н. А. Ганичев // Проблемы прогнозирования. - 2014. - № 1 (142). - С. 3-20.

Черных, С. Об участии российского бизнеса в финансировании научно-технологической сферы (экономические и идеологические аспекты) / С. Черных, Н. Фролова // Общество и экономика. -2018 . - № 11. - С. 86-97.

Численность населения с денежными доходами ниже величины прожиточного минимума. Динамические ряды // Федеральная служба государственной статистики. - Электрон. текстовые дан. - Режим доступа: http://www.gks. $\mathrm{ru} / \mathrm{wps} / \mathrm{wcm} /$ connect/rosstat_main/rosstat/ru/ statistics/population/level/\# (дата обращения: 02.05.2019). - Загл. с экрана.

Численность персонала, занятого научными исследованиями и разработками (по категориям; по субъектам Российской Федерации, движение персонала) // Федеральная служба государственной статистики. - Электрон. текстовые дан. - Режим доступа: http://www.gks.ru/ wps/wcm/connect/rosstat_main/rosstat/ru/ statistics/science and innovations/science/\# (дата обращения: 02.05.2019). - Загл. с экрана.

OECD Data (2019). - Electronic text data. - Mode of access: https://data.oecd.org/rd/gross-domesticspending-on-r-d.htm (date of access: 02.05.2019).Titlefrom screen.

\section{REFERENCES}

Badirova K.I., Slepnev D.M. Importozavisimost proizvodstva farmatsevticheskikh substantsiy kak problema lekarstvennoy bezopasnosti Rossiyskoy Federatsii [Import Dependence of the Production of Pharmaceutical Substances as a Problem of Drug Safety in the Russian Federation]. Innovatsii $v$ zdorove natsii : sb. materialov V Vseros. nauch.prakt. konf. s mezhdunar. uchastiem, g. SanktPeterburg, 8-9 noyab. 2017 g. [Innovation in the Health of the Nation. Collection of Materials of the $5^{\text {th }}$ All-Russian Scientific and Practical Conference with International Participation, Saint Petersburg, November 8-9, 2017]. Saint Petersburg, 2017, pp. 99-103.

Glazyev S.Yu., Arkhipova V.V. Otsenka vliyaniya sanktsiy i drugikh krizisnykh faktorov na sostoyanie rossiyskoy ekonomiki [Assessment of the Impact of Sanctions and Other Crisis Factors on the State of Russian Economy]. Rossiyskiy ekonomicheskiy zhurnal [Russian Economic Journal], 2018, no. 1, pp. 3-29. 
Grinberg R.S. Lyubov k sanktsiyam kak ekonomicheskiy mazokhizm [Love for Sanctions as an Economic Masochism]. Mir peremen. Mezhdunarodnyy nauchno-obshchestvennyy zhurnal, 2016, no. 3, pp. 5-7.

Denisov O.I., Falko S.G., Boyko V.P. Metodicheskie problemy i podkhody $\mathrm{k}$ otsenke rezultativnosti i effektivnosti NIOKR i innovatsiy [Methodological Problems and Approaches to Assessing the Effectiveness and Efficiency of $\mathrm{R} \& \mathrm{D}$ and Innovation]. Innovatsii $v$ menedzhmente [Innovations in Management], 2016, no. 2 (8), pp. 36-45.

Dolya vysokotekhnologichnykh i naukoemkikh otrasley ekonomiki v VVP [Share of High-Tech and Knowledge-Intensive Industries in the GDP]. Federalnaya sluzhba gosudarstvennoy statistiki [Federal State Statistics Service]. URL: http://www.gks.ru/wps/wcm/connect/rosstat main/rosstat/ru/statistics/efficiency/\# (accessed 2 May 2019).

Ermakova E.A., Larionov N.A. Nalogovye kredity v sisteme stimulirovaniya innovatsionnoy aktivnosti [Tax Credits in the System of Stimulating Innovation Activity]. Upravlenets [Upravlenets (The Manager)], 2015, no. 2 (54), pp. 4-10.

Ilyina I.E., Salitskaya E.A., Sergeeva O.L. Instrumenty gosudarstvennykh investitsiy $\mathrm{V}$ sektor issledovaniy i razrabotok i innovatsionnuyu deyatelnost: zarubezhnyy opyt [Tools for Public Investment in Research and Development and Innovation Activity: Foreign Experience]. Formirovanie novoy ekonomiki i klasternye initsiativy: teoriya i praktika [Formation of a New Economy and Cluster Initiatives: Theory and Practice]. Saint Petersburg, 2016, pp. 459-485.

Ilyina I.E. Zharova E.N. Instrumenty podderzhki issledovaniy i razrabotok vedushchikh otechestvennykh i zarubezhnykh nauchnykh fondov [Tools to Support Research and Development of Leading Domestic and Foreign Scientific Foundations]. Integratsiya obrazovaniya [Integration of Education], 2017, vol. 21 , no. 2 (87), pp. 164-183.

Ilyina I.E. Rezultativnost organizatsiy, osushchestvlyayushchikh nauchnuyu deyatelnost, kak indikator effektivnosti gosudarstvennykh raskhodov na NIOKR [Performance of Organizations Engaged in Scientific Activities as an Indicator of the Effectiveness of Public Spending on Research and Development]. Novaya ekonomicheskaya realnost, klasternye initsiativy i razvitie promyshlennosti (INPROM-2016): trudy Mezhdunar. nauch.-prakt. konf., 19-26 maya
2016 g. [New Economic Reality, Cluster Initiatives and Industrial Development (INPROM-2016). Proceedings of the International Scientific and Practical Conference, May 19-26, 2016]. Saint Petersburg, 2016. pp. 178-182.

Karnaukh I.V. Stanovlenie ekonomiki znaniy v Rossii: problemy i puti ikh resheniya [Formation of the Knowledge Economy in Russia: Problems and Solutions]. Vestnik Volgogradskogo gosudarstvennogo universiteta. Seriya 3, Ekonomika. Ekologiya [Science Journal of Volgograd State University. Global Economic System], 2019, vol. 21, no. 1, pp. 66-74. DOI: https:/ /doi.org/10.15688/jvolsu3.2019.1.6

Kachak V.V., Zhurikhin A.V., Maslennikov A.M. Adaptivnyy podkhod k formirovaniyu obyema finansirovaniya gosudarstvennogo zadaniya gosudarstvennym uchrezhdeniyam $\mathrm{v}$ chasti vypolneniya nauchnykh issledovaniy [Adaptive Approach to Forming the Volume of State Assignments to State Institutions in Implementing Scientific Research]. Innovatsii [Innovations], 2012, no. 7 (165), pp. 41-46.

Klypin A. V Rossii vyros VVP, a ne ekonomika, i eto ne rekord [The GDP Has Increased in Russia, not the Economy, and This is not a Record]. URL: https://echo.msk.ru/blog/aklypin/2367625-echo/ (accessed 2 May 2019).

Klypin A.V. Gosudarstvennoe finansirovanie prikladnoy nauki v Rossii [State Funding of Applied Science in Russia]. Nauka. Innovatsii. Obrazovanie [Science Governance and Scientometrics], 2016, no. 1 (19), pp. 34-54.

Klypin A.V., Agamirova E.V., Zharova E.N. Model «kvalifitsirovannogo zakazchika» v sfere NIOKR v Rossii: opredelenie osnovnykh svoystv i kharakteristik [Model of "Qualified Customer" in the Field of R\&D in Russia: Definition of Basic Properties and Characteristics]. Upravlenie naukoy i naukometriya [Science Governance and Scientometrics], 2019, no. 2 (14), pp. 224-247.

Kruglyak L.I. Ekonomika importozameshcheniya: realii i perspektivy [Economics of Import Substitution: Realities and Prospects]. Materialy Vseros. nauch.-prakt. konf. "Natsionalnaya bezopasnost Rossii: aktualnye aspekty» [Materials of the All-Russian Scientific and Practical Conference "National Security of Russia: Actual Aspects"]. Saint Petersburg, GNII «Natsrazvitie», 2018, pp. 46-52.

Kurakova N.G. Ob optimizatsii sistemy formirovaniya gosudarstvennogo zadaniya na vypolnenie rabot v sfere nauki [On the Optimizing the System of Forming the State Task for the Performance of Work in the Field of Science]. 
Ekonomika nauki [The Economics of Science], 2015, vol. 1, no. 3, pp. 221-235.

Mironova O.A. Problemy obespecheniya prodovolstvennoy bezopasnosti Rossii na makro- i mezourovne v usloviyakh vneshnetorgovykh sanktsiy [Problems of Ensuring Food Security of Russia at the Macro and Meso Level in the Conditions of Foreign Trade Sanctions]. Economics. Law. State, 2018, no. 1 (1), pp. 22-30.

Mikhaleva M.N. Modelirovanie izmeneniya chislennosti rossiyskikh issledovateley i prepodavateley vysshey shkoly [Modeling the Change in the Number of Russian Researchers and Teachers of Higher Education]. Rossiya reformiruyushchayasya, 2015, no. 13, pp. 347-359.

O dolgosrochnoy gosudarstvennoy ekonomicheskoy politike [On Long-Term State Economic Policy]. Access from Reference Legal System "ConsultantPlus". URL: http://www.consultant. $\mathrm{ru} /$ document/cons_doc_LAW_129343/(accessed 2 May 2019).

$O$ natsionalnykh tselyakh $i$ strategicheskikh zadachakh razvitiya Rossiyskoy Federatsii na period do 2024 goda [On National Goals and Strategic Development Objectives of the Russian Federation for the Period Until 2024]. URL: http://kremlin.ru/acts/bank/43027 (accessed 2 May 2019).

$\mathrm{O}$ proizvodstve $\mathrm{i}$ ispolzovanii valovogo vnutrennego produkta (VVP) za 2018 god [On the Production and Use of the Gross Domestic Product (GDP) for 2018]. Federalnaya sluzhba gosudarstvennoy statistiki [Federal State Statistics Service]. URL: http://www.gks.ru/bgd/free/b04_03/Isswww.exe/ $\mathrm{Stg} / \mathrm{d} 04 / 21 . \mathrm{htm}$ (accessed 2 May 2019).

O federalnom byudzhete na 2019 god i na planovyy period 2020 i 2021 godov [On the Federal Budget for 2019 and for the Planned Period of 2020 and 2021]. Access from Reference Legal System "ConsultantPlus". URL: http://www.consultant. ru/document/cons doc LAW 312362/ (accessed 2 May 2019).

Parfenova S.L., Zolotarev D.V., Grishakina E.G. Kachestvennye izmeneniya nauchnotekhnologicheskogo potentsiala Rossii [Qualitative Changes in the Scientific and Technological Potential of Russia]. Nauka. Innovatsii. Obrazovanie [Science Governance and Scientometrics], 2016, no. 1 (19), pp. 9-33.

Pasport natsionalnogo proekta «Nauka» [Passport of the National Project "Science"]. URL: http:// static.government.ru/media/files/vCAoi8zEXRV Suy2Yk7D8hvQbpbUSwO8y.pdf (accessed 2 May 2019).
Poslanie Prezidenta Federalnomu Sobraniyuv 2019 g. [Presidential Address to the Federal Assembly in 2019]. URL: http://www.kremlin.ru/events/ president/news/59863 (accessed 2 May 2019).

Programma «Sotsialnaya ipoteka»v Moskovskoy oblasti [Program "Social Mortgage" in Moscow Region]. URL: https://mosreg.ru/sobytiya/ infografika/programma-socialnaya-ipoteka-vmoskovskoy-oblasti (accessed 2 May 2019).

Sedash T.N., Tyutyukina E.B. Ispolzovanie zarubezhnogo opyta nalogovogo stimulirovaniya innovatsiy v Rossii [Using Foreign Experience in Tax Incentives for Innovation in Russia.]. Finansy $i$ kredit [Finance and Credit], 2018, vol. 24, no. 12 (780), pp. 2863-2875. DOI: https:// doi.org/10.24891/fc.24.12.2863

Stenogramma zasedaniya Soveta po nauke $i$ obrazovaniyu $v 2018 \mathrm{~g}$. [Transcript of the Meeting of the Council for Science and Education in 2018]. URL: http://www.kremlin.ru/ events/president/news/59203 (accessed 2 May 2019).

Tambovtsev V.L. O nauchnoy obosnovannosti nauchnoy politiki v RF [On Scientific Validity of Scientific Policy in the Russian Federation]. Voprosy Ekonomiki, 2018, no. 2, pp. 5-32.

Ushakov D.V. Sotsialno-politicheskie i ekonomicheskie osnovaniya deformatsii sotsiogumanitarnoy akademicheskoy nauki [Socio-Political and Economic Foundations of Socio-Humanitarian Academic Science Deformation]. Vestnik Khakasskogo gosudarstvennogo universiteta im. N.F. Katanova, 2018, no. 25, pp. 124-128.

Federalnye zakony ob ispolnenii federalnogo byudzheta (2013 -2017 gg.) [Federal Laws on the Execution of the Federal Budget (2013-2017)]. Access from Reference Legal System "ConsultantPlus". URL: http://www.consultant.ru/document/cons_doc_ LAW_169502/(accessed 2 May 2019).

Finansirovanie nauki iz sredstv federalnogo byudzheta [Financing Science from the Federal Budget]. Federalnaya sluzhba gosudarstvennoy statistiki [Federal State Statistics Service]. URL: http://www.gks.ru/wps/wcm/connect/rosstat_ main/rosstat $/ \mathrm{ru} / \mathrm{statistics} / \mathrm{science}$ and innovations/science/\# (accessed 2 May 2019).

Frolov I.E., Ganichev N.A. Nauchno-tekhnologicheskiy potentsial Rossii na sovremennom etape: problemy realizatsii i perspektivy razvitiya [Scientific and Technological Potential of Russia at the Present Stage. Problems of Implementation and Development Prospects]. Problemy prognozirovaniya [Studies on Russian Economic Development], 2014, no. 1 (142), pp. 3-20.

Chernykh S., Frolova N. Ob uchastii rossiyskogo biznesa $\mathrm{V}$ finansirovanii nauchno- 
tekhnologicheskoy sfery (ekonomicheskie i ideologicheskie aspekty) [On the Participation of Russian Business in Financing the Scientific and Technological Sphere (Economic and Ideological Aspects)]. Obshchestvo i ekonomika [Society and Economy], 2018, no. 11, pp. 86-97.

Chislennost naseleniya s denezhnymi dokhodami nizhe velichiny prozhitochnogo minimuma. Dinamicheskie ryady [Population with Cash Income Below the Subsistence Minimum. Statistical Series]. Federalnaya sluzhba gosudarstvennoy statistiki [Federal State Statistics Service]. URL: http://www.gks.ru/wps/ $\mathrm{wcm} /$ connect/rosstat main/rosstat/ru/statistics/ population/level/\# (accessed 2 May 2019).
Chislennost personala, zanyatogo nauchnymi issledovaniyami i razrabotkami (po kategoriyam; po subyektam Rossiyskoy Federatsii, dvizhenie personala) [The Number of Personnel Engaged in Research and Development (by Category; by Subjects of the Russian Federation, Personnel Movement)]. Federalnaya sluzhba gosudarstvennoy statistiki [Federal State Statistics Service]. URL: http://www.gks.ru/wps/ $\mathrm{wcm} / \mathrm{connect/rosstat} \mathrm{main} / \mathrm{ros} \operatorname{sat} / \mathrm{ru} /$ statistics/science_and_innovations/science/\# (accessed 2 May 2019).

OECD Data (2019). URL: https://data.oecd.org/rd/ gross-domestic-spending-on-r-d.htm (accessed 2 May 2019).

\section{Information about the Author}

Andrey V. Klypin, Candidate of Sciences (Economics), Head of the Sector of Analysis and Forecasting Development in the Field of Intellectual Property, Russian Research Institute of Economics, Politics and Law in Science and Technology (RIEPL), Dobrolyubova St., 20A, 127254 Moscow, Russian Federation, klypin@riep.ru, https://orcid.org/0000-0002-5735-0824

\section{Информация об авторе}

Андрей Владимирович Клыпин, кандидат экономических наук, заведующий сектором анализа и прогноза развития в области интеллектуальной собственности, Российский научно-исследовательский институт экономики, политики и права в научно-технической сфеpe (РИЭПП), ул. Добролюбова, 20A, 127254 г. Москва, Российская Федерация, klypin@riep.ru, https://orcid.org/0000-0002-5735-0824 